\title{
Effects of Glucagon and Prostacyclin in Acute Occlusive and Postocclusive Canine Mesenteric Ischemia ${ }^{1}$
}

\author{
David M. ShapiRo, M.D., JACK L. CRONENWETT, M.D., ${ }^{2}$ \\ S. Martin Lindenauer, M.D., Joshua L. LuCE, B.S., and James C. Stanley, M.D. \\ Division of Vascular Surgery, University of Michigan and Veterans \\ Administration Medical Center, Ann Arbor, Michigan 48109
}

Presented at the Annual Meeting of the Association for Academic Surgery, Syracuse, New York, November 2-5, 1983

\begin{abstract}
Effects of glucagon and prostacyclin $\left(\mathrm{PGI}_{2}\right)$ were studied in anesthetized dogs during sequential occlusive and postocclusive mesenteric ischemia induced by $90 \mathrm{~min}$ of toumiquet stenosis of the superior mesenteric artery (SMA). After $30 \mathrm{~min}$ of SMA stenosis, glucagon $(1 \mu \mathrm{g} / \mathrm{kg} / \mathrm{min}, n=7), \mathrm{PGI}_{2}(30 \mathrm{ng} /$ $\mathrm{kg} / \mathrm{min}, n=7$ ), or saline ( $1 \mathrm{ml} / \mathrm{min}, n=3$ ) was infused intravenously for $30 \mathrm{~min}$, followed by $30 \mathrm{~min}$ of continued ischemia. SMA flow and distal SMA pressure (SMAP) decreased 76\% with SMA stenosis $(P<0.01)$. Ileal wall flow measured by radiolabeled microspheres decreased from 45 to $13 \mathrm{ml} / \mathrm{min} /$ $100 \mathrm{~g}(P<0.01)$; mesenteric $\mathrm{AV} \mathrm{O}_{2}$ difference $\left(\mathrm{AVDO}_{2}\right)$ increased from 5.1 to $10.1 \mathrm{ml} / \mathrm{dl}(P<0.0 \mathrm{l})$; and mesenteric $\mathrm{O}_{2}$ consumption $\left(\mathrm{VO}_{2}\right)$ decreased by $48 \%(P<0.05)$. Glucagon infusion caused a further decrease in ileal wall flow, to $10 \mathrm{ml} / \mathrm{min} / 100 \mathrm{~g}(P<0.05)$, and an increase in $\mathrm{AVDO}_{2}$ to $11 \mathrm{ml} / \mathrm{dl}(P$ $<0.05$ ), despite a $22 \%$ increase in cardiac output. $\mathrm{PGI}_{2}$ caused a similar decrease in ileal wall flow and an increase in $\mathrm{AVDO}_{2}$, although these were not statistically significant. Saline infusion caused no change in measured variables. In the second phase of this study, SMA blood flow was restored by tourniquet release. After animals had stabilized for $30 \mathrm{~min}$, a repeat 30-min drug infusion was studied. In this postocclusive period, persistent gut ischemia was indicated by a reduction in $\mathrm{VO}_{2}$ to $76 \%$ of original baseline, associated with a $50 \%$ decrease in both $\mathrm{CO}$ and SMAQ. Intravenous infusion of glucagon at this time increased SMAQ by $195 \%(P<0.05)$ and resulted in a return of $\mathrm{VO}_{2}$ to its original baseline level. $\mathrm{PGI}_{2}$ infusion caused a $21 \%$ increase in SMAQ and a $16 \%$ decrease in $\mathrm{AVDO}_{2}$ (NS), but had no significant effect on $\mathrm{VO}_{2}$. Glucagon was effective in the management of postocclusive mesenteric ischemia but appeared to have a detrimental effect on ileal blood flow in severe occlusive ischemia.
\end{abstract}

Acute mesenteric ischemia may result from arterial occlusion or from nonocclusive states due to low systemic blood flow with secondary mesenteric vasoconstriction [22]. Superior mesenteric artery (SMA) infusion of vasodilating agents has been shown to effectively treat nonocclusive ischemia, in several animal models $[5,9,10,17,25,26]$ and in patients $[1,2,4,28]$. Acute occlusive mesenteric ischemia is appropriately treated by surgical reconstruction or arterial embolectomy. An unavoidable delay often occurs between presentation and definitive therapy, however, leading to irreversible ischemia and subsequent death

\footnotetext{
'Supported in part by a grant from the Michigan Heart Association and the Medical Research Service of the Veterans Administration.

${ }^{2}$ To whom requests for reprints should be addressed.
}

[22]. Little experimental attention has been focused on the ability of vasodilators to improve intestinal collateral blood flow in the presence of occlusive ischemia. In this study we investigated the usefulness of two intravenous mesenteric vasodilators, glucagon and prostacyclin $\left(\mathrm{PGI}_{2}\right)$, in a canine model of occlusive and postocclusive intestinal ischemia.

\section{MATERIALS AND METHODS}

Animal preparation. Mongrel dogs (17-37 $\mathrm{kg}$ ) that had been fasted overnight except for free access to water were anesthetized with intravenous pentobarbital sodium, $30 \mathrm{mg} / \mathrm{kg}$ initially, plus $2 \mathrm{mg} / \mathrm{kg} / \mathrm{hr}$ thereafter. Arterial blood gases and core temperature were maintained at their initial normal level by mechanical ventilation and external heating. All 
dogs received Ringer's lactate, $6 \mathrm{ml} / \mathrm{kg} / \mathrm{hr}$, throughout the experiment. A transjugular pulmonary artery Swan-Ganz catheter was used for thermodilution cardiac output (CO) measurement. A transcarotid $7 \mathrm{~F}$ catheter was passed into the left ventricle for radiolabeled microsphere injection and a transfemoral infrarenal aortic catheter was placed for microsphere reference sampling. Mean arterial pressure (MAP) was measured with a brachial artery catheter.

Through a midline laparotomy, the canine analog of the SMA was isolated at its origin and surrounded with a silk Rummel tourniquet. An electromagnetic flow probe was placed on the SMA distal to its middle colic branch to measure SMA flow (SMAQ). A distal ileal arterial branch and its corresponding vein were cannulated with 20 -gauge catheters to allow measurement of distal SMA pressure (SMAP) and sampling of mesenteric venous blood. After systemic heparinization (150 units $/ \mathrm{kg}$ initially and $15 \mathrm{units} / \mathrm{kg} / \mathrm{hr}$ thereafter), mesenteric venous and brachial arterial blood was circulated through a spectrophotometric oxygen analyzer (Avox Systems) for continuous determination of mesenteric AV oxygen difference $\left(\mathrm{AVDO}_{2}\right)$. Mesenteric oxygen consumption $\left(\mathrm{VO}_{2}\right)$ was calculated as $\mathrm{SMAQ} \times \mathrm{AVDO}_{2}\left(\mathrm{ml} / \mathrm{O}_{2} / \mathrm{min}\right)$. Mesenteric SMA vascular resistance (SMAR) was calculated as SMAP/SMAQ (peripheral resistance units, PRU), with the assumption that portal vein pressure contributed negligibly to this result. Portal vein pressure has been shown to change only 3-4 $\mathrm{mm} \mathrm{Hg}$ during glucagoninduced vasodilation [15]. Total peripheral resistance (TPR) was calculated as MAP/CO (PRU), assuming central venous pressure (CVP) changes to be negligible. CVP was measured in $\mathrm{PGI}_{2}$-treated animals.

In addition to SMA flowmetry, intestinal blood flow was quantitated by the uptake of $15-\mu \mathrm{m}$ diameter, radiolabeled microspheres. Four isotopes, ${ }^{141} \mathrm{Ce},{ }^{85} \mathrm{Sr},{ }^{95} \mathrm{Nb}$, and ${ }^{113} \mathrm{Sn}$, suspended in $10 \%$ dextran, allowed determination of blood flow at four different time points. Microspheres, $400,000-800,000$ in number, were injected rapidly through the left ventricular catheter which was then flushed with $10 \mathrm{ml}$ saline. An aortic reference sample was withdrawn at $15 \mathrm{ml} / \mathrm{min}$, beginning 10 sec prior to injection and continuing for 2 min. At the conclusion of the experiment, 10$\mathrm{cm}$ segments of terminal ileum and proximal jejunum were removed and divided in half longitudinally. Half of each segment of ileum and jejunum was then separated into muscularis and mucosa-submucosa layers [12], and these, together with the full-thickness wall segments, were blotted dry, weighed, and placed in formalin-containing vials for scintillation counting. Intestinal tissue and blood reference samples were assayed in a Beckman 8000 gamma scintillation detector for the specific energy of each isotope. Data were recorded by a microcomputer programmed to perform isotope spectral separation and calculation of intestinal blood flow by the reference sample technique [24]. Following isotope assays tissue samples were prepared for light microscopy by hematoxylin and eosin staining.

Part 1. Occlusive mesenteric ischemia. After completing the above preparation, dogs were allowed to stabilize for $30 \mathrm{~min}$, and baseline data were recorded. SMA stenosis was then induced by tightening the Rummel tourniquet to produce a $75 \%$ flow reduction as measured by SMA flowmetry. After $30 \mathrm{~min}$ of ischemia, intravenous glucagon, $1 \mu \mathrm{g} / \mathrm{kg} / \mathrm{min}(n=7)$; $\mathrm{PGI}_{2}, 30 \mathrm{ng} / \mathrm{kg} / \mathrm{min}(n=7)$; or saline alone, $1 \mathrm{ml} / \mathrm{min}(n=3$, a volume equivalent to that used to deliver the other drugs) was infused for $30 \mathrm{~min}$. $\mathrm{PGI}_{2}$ was prepared from the sodium salt by dissolution in glycine buffer at $\mathrm{pH} 10$ to ensure stability. The $\mathrm{PGI}_{2}$ solution was stored on ice and aliquots were removed as needed for infusion. After drug treatment, tourniquet stenosis was maintained for an additional $30 \mathrm{~min}$ and then released to allow restoration of SMA blood flow. Microsphere injections were made at the end of the first four 30-min observation periods: baseline, SMA stenosis, treatment, and post treatment (Fig. 1).

Part 2. Postocclusive mesenteric ischemia. After restoration of SMA blood flow, animals 


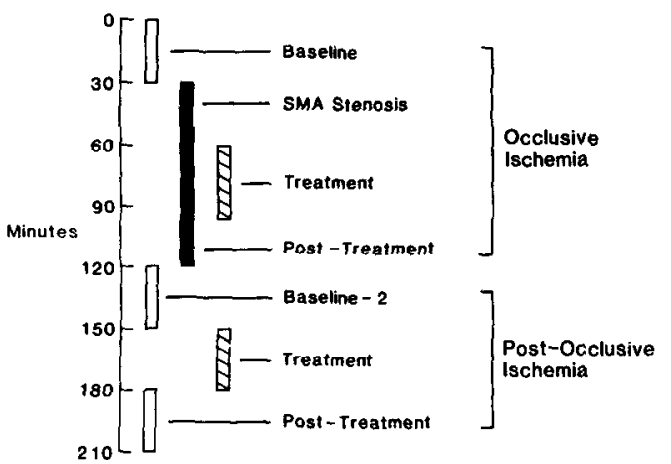

FIG. 1. Experimental protocol for Part 1, occlusive mesenteric ischemia, and Part 2, postocclusive mesenteric ischemia.

were allowed to stabilize for $30 \mathrm{~min}$ before Part 2 of this study. Dogs that had received either glucagon or $\mathrm{PGI}_{2}$ then received a second 30-min infusion of the same drug and dose. After this repeat infusion, animals were monitored for an additional $30 \mathrm{~min}$ prior to sacrifice and removal of tissue samples (Fig. 1). Data were computerized and analyzed within each treatment group between successive time points and between treatment groups at each time point by analysis of variance. If overall significant $(P<0.05)$ changes were found by analysis of variance, Student's two-tailed $t$ test was applied to the individual values to determine specific differences. For statistical comparison, data were normalized to their baseline value to reduce interdog variance.

\section{RESULTS}

\section{Part 1. Occlusive Ischemia}

Baseline hemodynamic measurements revealed no significant difference between control, glucagon, and $\mathrm{PGI}_{2}$ animals prior to treatment except that $\mathrm{PGI}_{2}$ animals had a higher MAP (and SMAP) (Table 1). SMA stenosis caused a small decrease in $\mathrm{CO}$ and an increase in TPR, with unchanged MAP. SMAQ decreased to $26 \%$ of baseline, as expected from the experimental design (Fig. 2). This represented a reduction in the percentage of CO distributed to the SMA from 5.7 to $1.5 \%(P<0.0001)$ and was accompanied by a decrease in SMAP to $26 \%$ of baseline. There was no significant change in calculated SMAR (Table 1). Microsphere measured ileal wall blood flow after SMA stenosis decreased to $30 \%$, ileal mucosal flow to $39 \%$, jejunal wall flow to $38 \%$, and jejunal mucosal flow to $36 \%$ of baseline (all $P<0.0001$, Fig. 3). Although mesenteric $\mathrm{AVDO}_{2}$ increased to $209 \%$ of baseline during this low flow period, $\mathrm{VO}_{2}$ decreased to $52 \%$ of its baseline value ( $P$ $<0.0001$, Fig. 4).

Glucagon infusion during SMA stenosis caused a $22 \%$ increase in $\mathrm{CO}$ that persisted during the infusion and terminated when the drug was stopped. In this respect, glucagon infusion differed statistically from $\mathrm{PGI}_{2}$ and saline infusion, where $\mathrm{CO}$ decreased progressively during SMA stenosis (Table 1). Systemic MAP decreased gradually during the entire experiment, with small changes that did not appear to be related to drug treatment. Glucagon infusion did cause a $12 \%$ decrease in TPR $(P<0.01)$ with a $43 \%$ increase in TPR noted upon stopping the drug $(P<0.05)$. SMAQ decreased significantly during glucagon infusion, from 37 to $19 \mathrm{ml} / \mathrm{min}$ after $30 \mathrm{~min}$ infusion $(P<0.05)$, returning to $31 \mathrm{ml} / \mathrm{min}$ after the glucagon infusion stopped $(P=0.11)$. This decrease in SMAQ was associated with a significant reduction in SMAP, from 39 to $28 \mathrm{~mm} \mathrm{Hg}(P<0.01)$. A concomitant increase in $\mathrm{AVDO}_{2}$ was seen during glucagon infusion, from 10.8 to $12.5 \mathrm{ml} \mathrm{O}_{2} / \mathrm{dl}(P<0.01$, Fig. 4). Mesenteric $\mathrm{VO}_{2}$ tended to decrease during glucagon infusion, from 3.8 to $2.4 \mathrm{ml} / \mathrm{O}_{2} / \mathrm{min}$, but this fall was not statistically significant. Distal ileal wall blood flow decreased from 16 to $10 \mathrm{ml} / \mathrm{min} / 100 \mathrm{~g}$ during glucagon infusion $(P<0.05$, Fig. 3). It is noteworthy that this $38 \%$ reduction in flow was different $(P<0.05)$ from saline control animals where ileal wall flow increased $10 \%$. Ileal and jejunal mucosal blood flow, and jejunal wall blood flow decreased 54,22 , and $18 \%$, respectively, during glucagon infusion, but these changes were not statistically significant (Table 2).

$\mathrm{PGI}_{2}$-treated dogs showed progressively decreased $\mathrm{CO}$ and MAP during the experiment, with an increasing TPR, that did not seem to 


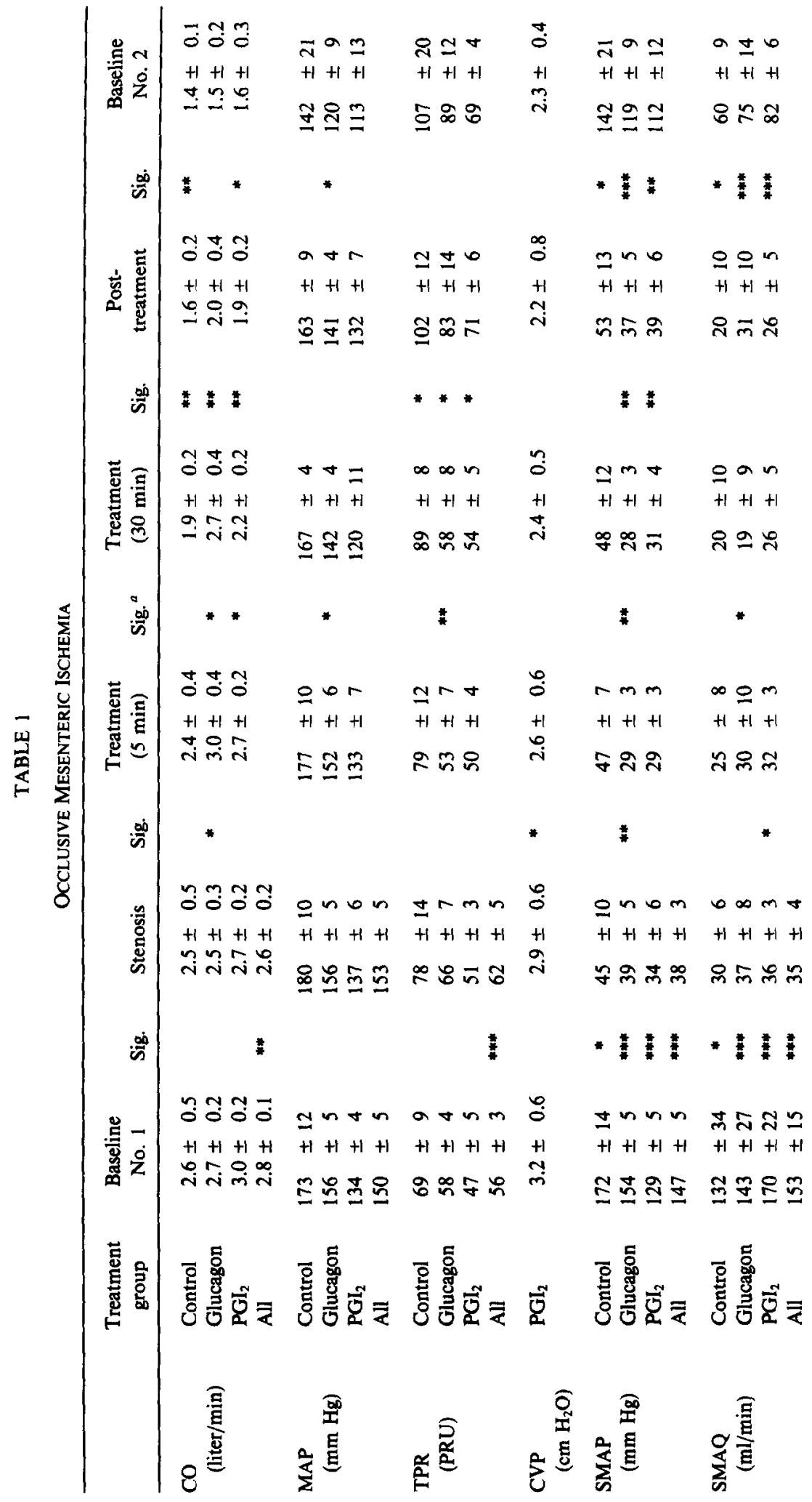




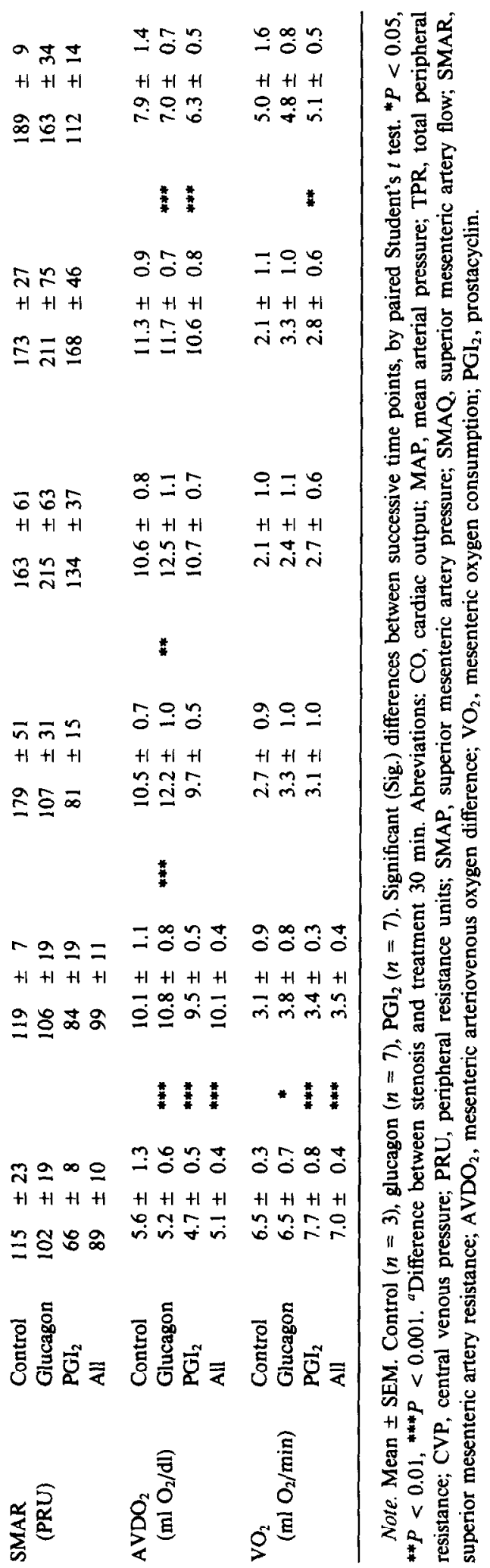

be related to drug infusion. SMAQ decreased $11 \%$ during $\mathrm{PGI}_{2}$ infusion $(P<0.05)$ but did not increase after the infusion had stopped. $\mathrm{AVDO}_{2}$ tended to increase during $\mathrm{PGI}_{2}$ infusion $(P=0.06)$, so that $\mathrm{VO}_{2}$ was unchanged (Fig. 4). Microsphere measured ileal wall blood flow decreased $42 \%$ during $\mathrm{PGI}_{2}$ infusion, which was nearly statistically significant $(P$ $=0.06$ ) when compared with control animals (Fig. 3). Comparable reductions in flow were seen in mucosal flow of the distal ileum, as well as in jejunal wall and mucosal layers, although none of these decreases was statistically significant in this small group of animals (Table 2).

Saline-infused dogs, like $\mathrm{PGI}_{2}$-treated animals, exhibited a progressive decrease in $\mathrm{CO}$ during Part 1 (occlusive phase) of this experiment that reached statistical significance by the post-treatment period (Table 1). No significant change was seen in MAP, although TPR showed a slow, gradual increase. As opposed to glucagon- or $\mathrm{PGI}_{2}$-treated animals, saline control dogs showed no change in SMAP, SMAQ, $\mathrm{AVDO}$, or $\mathrm{VO}_{2}$ during the 30-min infusion period. Similarly, ileal and jejunal whole wall and mucosal-submucosal flows were not significantly changed and, in fact, tended to increase slightly during the saline infusion (Table 2, Fig. 3).

Based on known radioactivity per microsphere, all tissue samples were determined to contain more than 400 spheres from baseline blood flow measurements. During ischemia, most samples contained at least 250 spheres, although some contained as few as 100 spheres, due to the extremely low flow. Although sampling error is inversely proportional to the number of spheres/sample, the relative impact of this error at such low flow is minimal [6]. Mucosa-submucosa received 92 and $80 \%$ of total wall flow in the jejunum and ileum, respectively, while the muscularis layer received 8 and $20 \%$ of flow. Because muscularis samples often contained less than 50 spheres per sample during ischemia, muscularis flow data were considered inadequate for accurate microsphere sampling and were not analyzed further. 

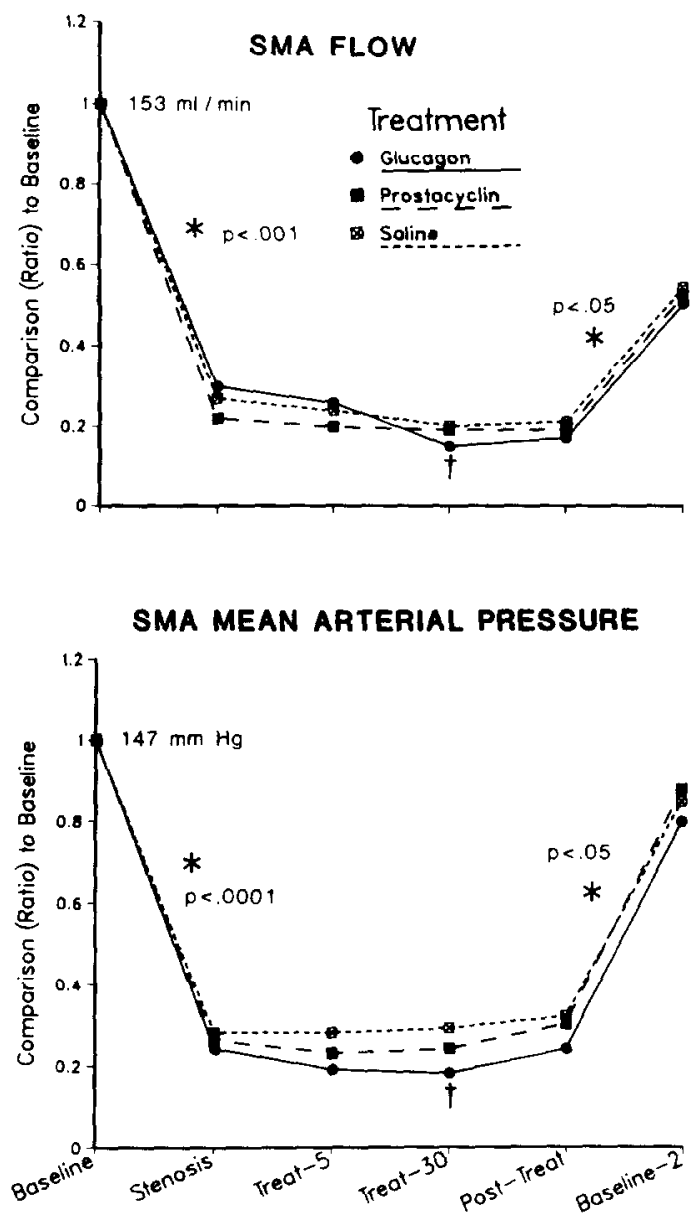

FIG. 2. SMA flow and pressure during Part 1 , occlusive ischemia. Data expressed as ratio to initial baseline. †A significant $(P<0.05)$ decrease in both SMA flow and pressure occurred during glucagon treatment.

\section{Part 2. Postocclusive Ischemia}

After SMA stenosis was released, during Part 2 of this experiment, measured variables were compared to baseline data. $\mathrm{CO}$ fell to $54 \%$ of baseline for all dogs studied, statistically significant for each treatment group (Table 3). MAP decreased to $80 \%$ of its original level, which was most significant in glucagon-treated dogs. TPR rose to approximately 1.5 times baseline in all groups. SMAQ stabilized at $49 \%$ of its original baseline values $30 \mathrm{~min}$ after release of the SMA tourniquet (Fig. 5). The percentage of $\mathrm{CO}$ distributed to the SMA at this point was $4.5-5.5 \%$. Since this was not significantly different from baseline percentages, it implied a nonselective reduction in SMAQ, comparable to the degree of flow reduction seen in the entire systemic circulation. SMAR increases of $60-70 \%$ compared to baseline were comparable to the increases in TPR of $46-53 \%$ (Table 3). After release of SMA stenosis, $\mathrm{AVDO}_{2}$ decreased, but not to baseline levels. Similarly, mesenteric $\mathrm{VO}_{2}$ increased, but to only $66-75 \%$ of the initial baseline value (Fig. 4).

Infusion of $\mathrm{PGI}_{2}$ in the postocclusive period caused few hemodynamic changes. There was a tendency for an early $(5 \mathrm{~min}$ ) decrease in MAP and increase in $\mathrm{CO}$ that did not persist. SMAQ increased $27 \%$ during early infusion
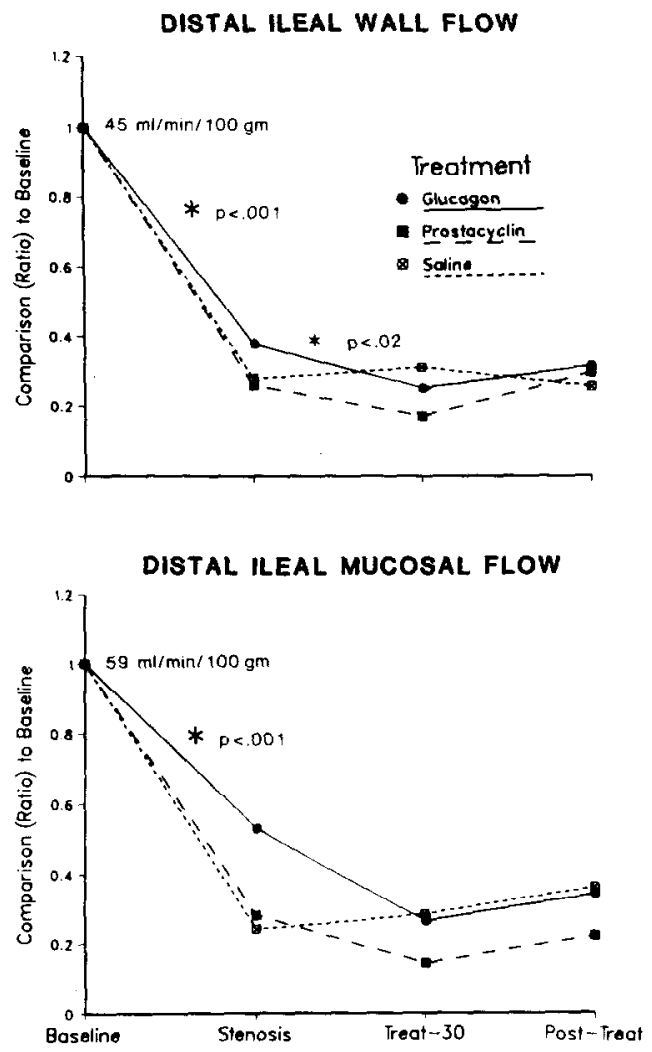

FIG. 3. Microsphere-determined ileal whole-wall and mucosal-submucosal blood flow during Part 1, occlusive ischemia. After tourniquet stenosis, ileal whole-wall flow decreased further during glucagon treatment. 

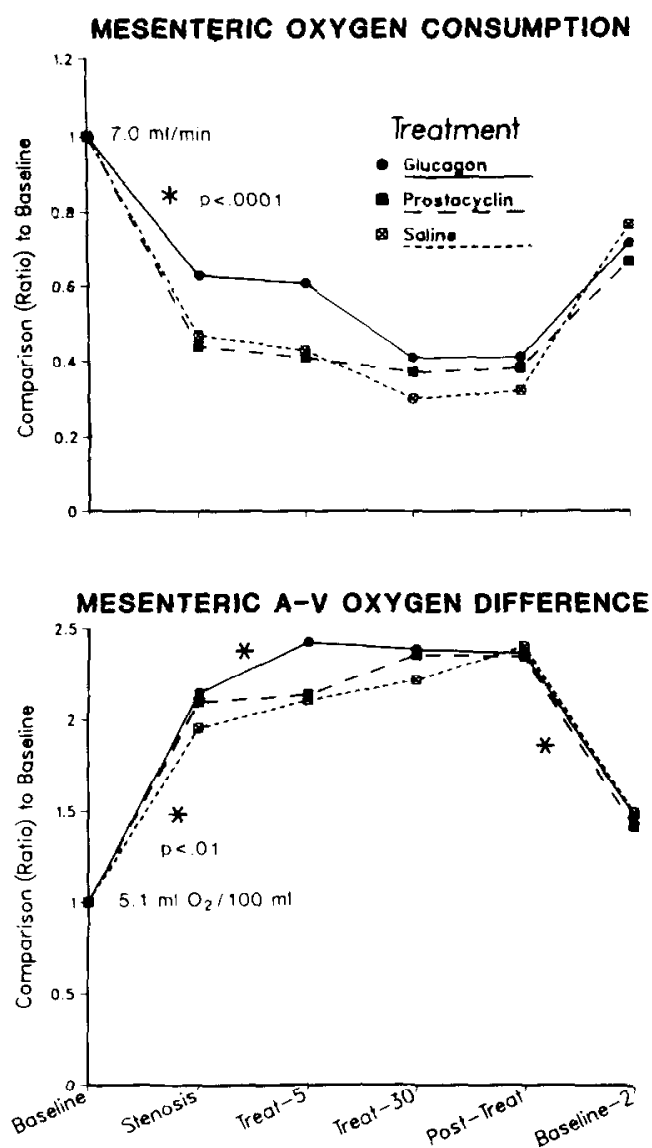

FIG. 4. Mesenteric AV oxygen difference and oxygen consumption during Part 1, occlusive ischemia. AV oxygen difference increased to maintain stable oxygen consumption during glucagon trcatment.

and was associated with a corresponding $17 \%$ decrease in $\mathrm{AVDO}_{2}$. These effects were not sustained, however, and did not achieve statistical significance. Mesenteric $\mathrm{VO}_{2}$ decreased progressively during this phase of the experiment and was unaffected by $\mathrm{PGI}_{2}$ infusion (Fig. 5). CVP showed a gradually decreasing value from 3.2 to $1.9 \mathrm{~cm} \mathrm{H}_{2} \mathrm{O}$ over the course of the study $(P<0.05)$.

Glucagon infusion during Part 2 of this experiment was associated with major hemodynamic alterations. SMAQ increased from 75 to $221 \mathrm{ml} / \mathrm{min}$ by $5 \mathrm{~min}(P<0.001)$, a change that persisted throughout drug infusion (Fig. 5). This was associated with a $75 \%$ re- duction in SMAR, a $50 \%$ decrease in $\mathrm{AVDO}_{2}$, and a restoration of mesenteric $\mathrm{VO}_{2}$ to its original baseline level (Table 3 ). Despite these major increases in mesenteric flow, insignificant increases in CO occurred. TPR decreased by $50 \%$, significantly less than an observed $75 \%$ decrease in SMAR $(P<0.05)$. These effects of glucagon infusion were statistically different from the effects of $\mathrm{PGI}_{2}$ infusion (Table 3, Fig. 5). During glucagon infusion, the percentage of $\mathrm{CO}$ distributed to the SMA increased from 4.8 to $11.2 \%(P<0.01)$.

Histologic examination of ischemic ileum and jejunum demonstrated a spectrum of ischemic change from virtually no abnormality to hemorrhagic necrosis of most of the villus layer. This variation appeared to represent local sampling effects or dog-specific differences, since no correlation could be made
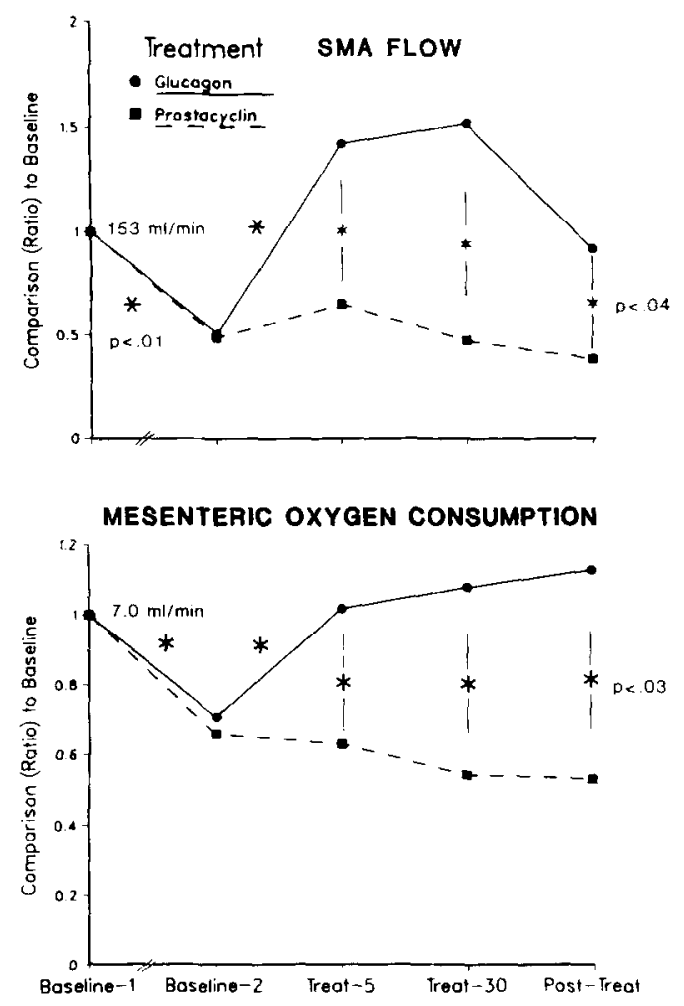

FiG. 5. SMA blood flow and mesenteric oxygen consumption during Part 2, postocclusive ischemia. Glucagon normalized oxygen consumption due to a large increase in SMA flow not seen during prostacyclin treatment. 
TABLE 2

OCCLUSIVE MESENTERIC ISCHEMIA ${ }^{a}$

\begin{tabular}{|c|c|c|c|c|c|c|c|c|}
\hline & $\begin{array}{l}\text { Treatment } \\
\text { group }\end{array}$ & Baseline & Sig. & Stenosis & Sig. & $\begin{array}{l}\text { Treatment } \\
\text { (30 min) }\end{array}$ & Sig. & $\begin{array}{c}\text { Post- } \\
\text { treatment }\end{array}$ \\
\hline $\begin{array}{l}\text { Ileal wall flow } \\
\qquad(\mathrm{ml} / \mathrm{min} / 100 \mathrm{~g})\end{array}$ & $\begin{array}{l}\text { Control } \\
\text { Glucagon } \\
\mathrm{PGI}_{2} \\
\text { All }\end{array}$ & $\begin{array}{l}46 \pm 11 \\
42 \pm 5 \\
48 \pm 2 \\
45 \pm 3\end{array}$ & $\underset{* * *}{* * *}$ & $\begin{array}{l}10 \pm 4 \\
16 \pm 3 \\
12 \pm 3 \\
11 \pm 2\end{array}$ & * & $\begin{array}{r}11 \pm 5 \\
10 \pm 3 \\
7 \pm 2\end{array}$ & & $\begin{array}{r}9 \pm 4 \\
12 \pm 2 \\
12 \pm 3\end{array}$ \\
\hline $\begin{array}{l}\text { Ileal mucosal flow } \\
(\mathrm{ml} / \mathrm{min} / 100 \mathrm{~g})\end{array}$ & $\begin{array}{l}\text { Control } \\
\text { Glucagon } \\
\mathrm{PGI}_{2} \\
\text { All }\end{array}$ & $\begin{array}{l}60 \pm 12 \\
56 \pm 12 \\
61 \pm 2 \\
59 \pm 6\end{array}$ & $\begin{array}{c}* \\
* \\
* * \\
* * *\end{array}$ & $\begin{array}{l}12 \pm 5 \\
28 \pm 10 \\
18 \pm 4 \\
14 \pm 3\end{array}$ & & $\begin{array}{r}14 \pm 6 \\
13 \pm 5 \\
7 \pm 2\end{array}$ & & $\begin{array}{l}18 \pm 9 \\
17 \pm 3 \\
10 \pm 3\end{array}$ \\
\hline $\begin{array}{l}\text { Jejunal wall flow } \\
(\mathrm{ml} / \mathrm{min} / 100 \mathrm{~g})\end{array}$ & $\begin{array}{l}\text { Control } \\
\text { Glucagon } \\
\mathrm{PGI}_{2} \\
\text { All }\end{array}$ & $\begin{array}{l}80 \pm 37 \\
51 \pm 10 \\
60 \pm 8 \\
61 \pm 9\end{array}$ & $\begin{array}{l}* * \\
* * \\
* * *\end{array}$ & $\begin{array}{l}33 \pm 5 \\
17 \pm 4 \\
24 \pm 8 \\
23 \pm 4\end{array}$ & & $\begin{array}{l}27 \pm 5 \\
14 \pm 5 \\
18 \pm 6\end{array}$ & & $\begin{array}{l}30 \pm 9 \\
16 \pm 6 \\
16 \pm 5\end{array}$ \\
\hline $\begin{array}{l}\text { Jejunal mucosal flow } \\
(\mathrm{m} / \mathrm{min} / 100 \mathrm{~g})\end{array}$ & $\begin{array}{l}\text { Control } \\
\text { Glucagon } \\
\mathrm{PGI}_{2} \\
\text { All }\end{array}$ & $\begin{array}{l}97 \pm 39 \\
55 \pm 8 \\
80 \pm 11 \\
73 \pm 10\end{array}$ & $\stackrel{* *}{* *}$ & $\begin{array}{l}37 \pm 4 \\
18 \pm 4 \\
29 \pm 9 \\
23 \pm 4\end{array}$ & & $\begin{array}{l}37 \pm 8 \\
14 \pm 4 \\
20 \pm 7\end{array}$ & & $\begin{array}{l}40 \pm 10 \\
15 \pm 5 \\
21 \pm 6\end{array}$ \\
\hline
\end{tabular}

Note. Mean \pm SEM. Control $(n=3)$, glucagon $(n=7), \mathrm{PGI}_{2}(n=7)$. Significant (Sig.) differences between successive time points by paired Student's $t$ test. ${ }^{*} P<0.05,{ }^{* *} P<0.01,{ }^{* * *} P<0.001$. Abbreviations: $\mathrm{PGI}_{2}$, prostacyclin. "Microsphere-measured intestinal blood flow.

between the degree of histologic change and the drug treatment groups.

\section{DISCUSSION}

In this study, mesenteric ischemia due to severe SMA stenosis resulted in histologic damage comparable to that seen after SMA occlusion $[7,29]$. This degree of stenosis prevented autoregulation of intestinal blood flow, as demonstrated by comparable $75 \%$ reductions in both pressure and flow in the distal mesenteric circulation [11]. Villus tip loss in ischemic intestinal segments could result in an underestimate of mucosal blood flow if sufficient microspheres were lost in sloughed villus tips. Based on our pathologic evaluation, this effect would have been similar in all treatment groups and would have affected baseline, stenosis, treatment, and post-treatment values equally. Microsphere-measured flow changes were corroborated by both flow meter SMAQ measurement and corresponding changes in mesenteric $\mathrm{AVDO}_{2}$. Furthermore, the ratio of microsphere distribution between submucosa-mucosa segments and muscularis segments observed throughout this experiment agrees with that previously reported by other investigators in normal intestine $[12,20]$. It is therefore unlikely that villus tip necrosis resulted in spurious microsphere blood flow determinations during either glucagon or $\mathrm{PGI}_{2}$ infusion.

Pilot studies in our laboratory, as well as published reports, have demonstrated that the dose of glucagon and $\mathrm{PGI}_{2}$ used in this study will significantly increase intestinal blood flow in dogs that have normal mesenteric flow $[8$, $15,19,23,27]$. Direct SMA administration of these agents has been shown to increase blood flow in animal models of nonocclusive intestinal ischemia produced by hemorrhage, digitalis, and endotoxin $[5,9,10,17,25]$. Nonocclusive ischemia results from mesenteric vasoconstriction secondary to low systemic blood flow and augmented sympathetic 


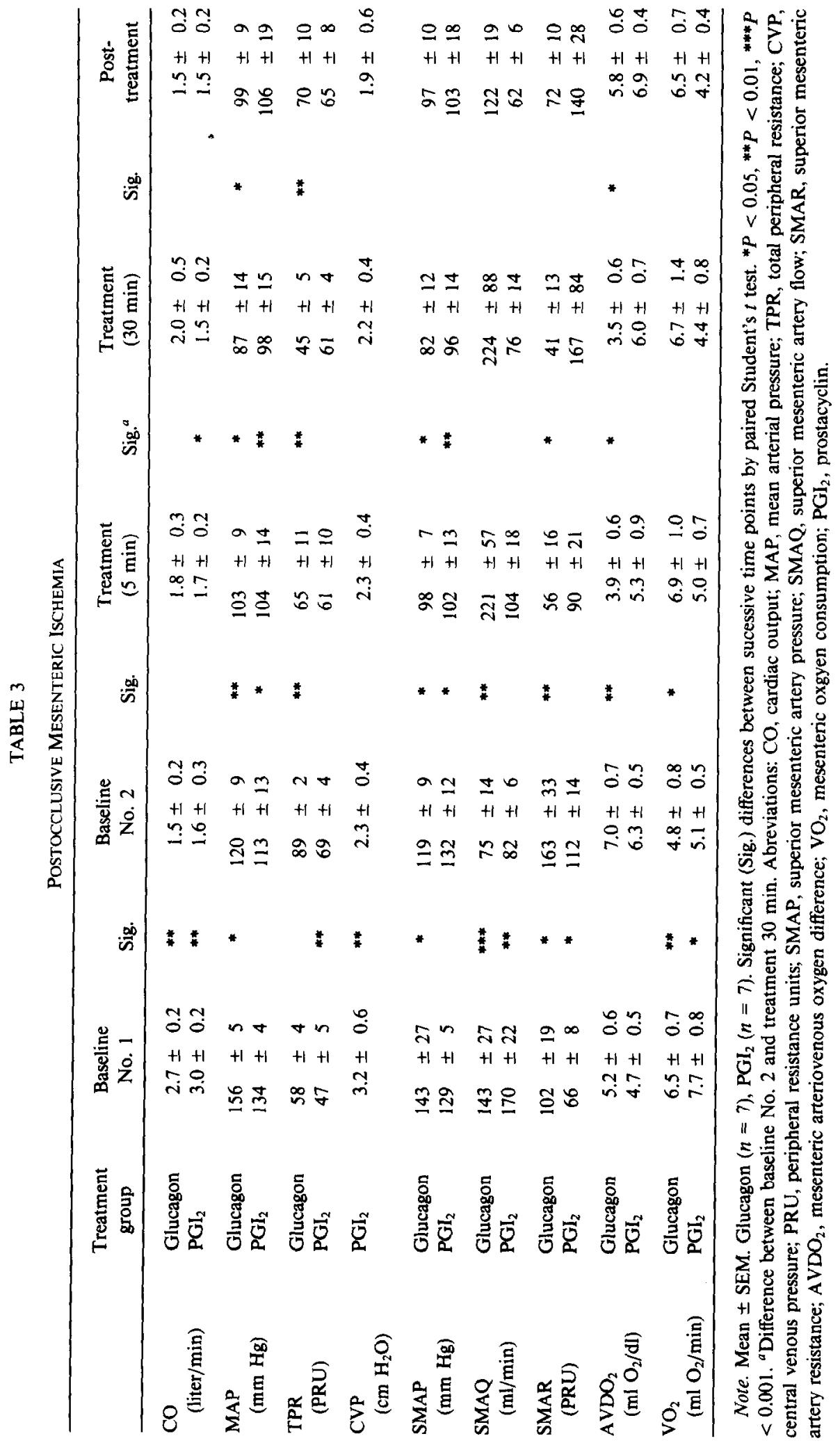


activity. Direct-acting arterial smooth muscle relaxants effectively overcame this vasoconstriction to increase intestinal blood flow. This effect requires adequate circulatory volume, without which, mesenteric vasodilation can result in cardiovascular collapse [5].

During occlusive ischemia, intravenous mesenteric vasodilators were unable to improve blood flow, presumably because maximal local vasodilation had already occurred. Although not directly measured in our study, blood flow to other splanchnic areas that were not affected by ischemia may have been augmented by vasodilator infusion [26]. This could theoretically have resulted in a diversion of blood flow away from ischemic intestine, particularly if total vascular volume was marginal. The statistically significant decrease in ileal wall blood flow observed during glucagon infusion supports this argument. Concomitant increases in CO and decreases in TPR strongly suggest that a limited vascular reserve was diverted to nonischemic areas capable of vasodilation. Although continuous infusion of Ringer's lactate was calculated to replace insensible and laparotomy-induced fluid losses, this did not prevent a gradual reduction in CVP in these animals. Larger infusions of crystalloid or plasma might have prevented the reduction of ileal blood flow seen during glucagon treatment. The importance of concomitant fluid resuscitation when using mesenteric vasodilators in the clinical setting has been previously emphasized $[1,4,5,21,22]$.

In addition to ischemic terminal ileum, we measured blood flow in a proximal jejunal segment that we predicted would represent an area of marginal ischemia, due to its proximity to celiac collateral vessels. This did not prove to be the case since comparable decreases in blood flow were seen in both the jejunum and ileum. This result, however, may depend on the anatomic details of the animal model used and may not accurately portray the effectiveness of intestinal collateral circulation in humans.

The minimal effects of glucagon and $\mathrm{PGI}_{2}$ during occlusive ischemia prompted us to ver- ify the reactivity of the intestinal circulation to these intravenous agents during the postocclusive state (Part 2 of this experiment). Such a model has, in fact, been extensively used to study nonocclusive intestinal ischemia, since a significant intestinal vasoconstrictive period follows mechanical obstruction of the SMA $[3,4,13,14,18,21,29]$. Results of our study support the conclusion that mesenteric vascular resistance increases or remains elevated after the release of a mechanical SMA stenosis and that SMAQ, as well as $\mathrm{VO}_{2}$, do not return to normal. In this setting, intravenous glucagon rapidly restored intestinal $\mathrm{VO}_{2}$ to normal by reversing mesenteric vasoconstriction, an effect that persisted for the duration of glucagon infusion and was quite specific for the intestinal vascular bed, as judged by minimal changes in systemic TPR and $\mathrm{CO}$. In the same situation, $\mathrm{PGI}_{2}$ infusion resulted in only a transient, minimal SMAQ increase. This was somewhat unexpected since comparable doses of $\mathbf{P G I}_{2}$ caused a twofold increase in SMAQ when infused into normal dogs during our pilot experiments. The lack of effect of $\mathrm{PGI}_{2}$ during postocclusive ischemia may be due to changes in the systemic status of the animals, including hypovolemia and cardiac depression. Although prolonged barbituate anesthesia undoubtedly contributes to reduced cardiac function, increasing evidence suggests that a polypeptide released from ischemic intestine may impart significant cardiac depression after primary intestinal ischemia $[13,14,18]$. Our data indicate that mesenteric vasoconstriction paralleled the increases in TPR, since the percentage of CO distributed to the SMA remained constant. The ability of glucagon to enhance or stabilize cardiac performance during concomitant mesenteric vasodilatation may account for its ability to augment mesenteric blood flow, as opposed to $\mathrm{PGI}_{2}$, which does not share these direct myocardial effects. These characteristics would appear to make glucagon an ideal intravenous agent for treatment of nonocclusive mesenteric ischemia that follows a previous occlusive event. The potential value of $\mathrm{PGI}_{2}$ in the 
treatment of mesenteric ischemia requires further investigation. Theoretically, the ability of $\mathrm{PGI}_{2}$ to inhibit platelet aggregation might play an important role in low-flow situations where thrombotic intestinal occlusion occurs clinically. In our model, the necessity for heparinization, in order to continuously sample blood for intestinal $\mathrm{AVDO}_{2}$ measurement, prevented us from studying this effect.

Kazmers et al. recently reported that IV glucagon, and to a lesser extent, $\mathrm{PGI}_{2}$, improved survival in rats after $85 \mathrm{~min}$ of SMA occlusion [16]. Drug infusions were begun 15 min after initiating SMA occlusion and were continued for 20 min after releasing the occlusion. Animals received extensive saline infusion $(17 \mathrm{ml} / \mathrm{kg} / \mathrm{min})$ and systemic cardiovascular effects were not measured. It is not clear, therefore, whether improved survival was due to the combination of fluid replacement and vasodilators, cardiac inotropic support, or treatment in the postocclusive period. Our study suggests that the use of glucagon in association with occlusive mesenteric ischemia should be reserved for the time period immediately following surgical reconstruction, when the effects of secondary mesenteric vasoconstriction may be formidable. Although caution must be exercised in the transference of laboratory data to clinical practice, these data further suggest that glucagon may have detrimental effects on blood flow to an isolated, ischemic intestinal segment, particularly in the presence of inadequate vascular volume. Further investigation of the appropriate timing of vasodilator therapy in association with occlusive ischemia is necessary to better define the value of such pharmacologic intervention.

\section{ACKNOWLEDGMENTS}

John E. Pike, D. Phil., Upjohn Company, kindly provided prostacyclin for this study.

\section{REFERENCES}

1. Aldrete, J. S., Han, S., Laws, H. L., and Kirklin, J. W. Intestinal infarction complicating low cardiac output states. Surg. Gynecol. Obstet. 144: 371, 1977.

2. Athanasoulis, C. A., Wittenberg, J., Bernstein, R., and Williams, L. F. Vasodilatory drugs in the man- agement of nonocclusive bowel ischemia. Gastroenterology 68: 146, 1975.

3. Boley, S. J., Regan, J. A., Tunick, P. A., Everhard, M. E., Winslow, P. R, and Veith, F. J. Persistent vasoconstriction-A major factor in non-occlusive mesenteric ischemia. Curr. Topics Surg. Res. 3: 425, 1971.

4. Boley, S. J., Sprayregan, S., Siegelman, S. S., and Veith, F. J. Initial results from an aggressive roentgenological and surgical approach to acute mesenteric ischemia. Surgery 88: 848, 1977.

5. Bond, J. H., and Levitt, M. D. Effect of glucagon on gastrointestinal blood flow of dogs in hypovolemic shock. Amer. J. Physiol. 238: G434, 1980.

6. Buckberg, G. D., Luck, J. C., et al. Some sources of error in measuring regional blood flow with radioactive microspheres. J. Appl. Physiol. 31: 598, 1971.

7. Cassuto, J., Cedgard, S., Haglund, U., Redfors, S., and Lundgren, $\mathrm{O}$. Intramural blood flows and flow distribution in the feline small intestine during arterial hypotension. Acta Phys. Scand. 106: 335, 1979.

8. Chapnick, B. M., Feigen, L. P., Hyman, A. L., and Kadowitz, P. J. Differential effects of prostaglandins in the mesenteric vascular bed. Amer. $J$. Physiol. 235: H326, 1978.

9. Fondacaro, J. D., Schwaiger, M., and Jacobson, E. D. Effects of vasodilators on mesenteric ischemia and hypoxia induced by hemorrhage. Circ. Shock 6: 255, 1979.

10. Fondacaro, J. D., Walus, K. M., Schwaiger, M., and Jacobson, E, D. Vasodilation of the normal and ischemic canine mesenteric circulation. Gastroenterology 80: $1542,1981$.

11. Granger, D. N., Kvietys, P. R., and Perry, M. A. Role of exchange vessels in the regulation of intestinal oxygenation. Amer. J. Physiol. 242: G570, 1982.

12. Greenway, C. V., and Murthy, V, S. Effects of vasopressin and isoprenaline infusions on the distribution of blood flow in the intestine; criteria for the validity of microsphere studies. Brit. J. Pharmacol. 46: $177,1972$.

13. Haglund, U., Lundholm, K., Lundgren, O., and Schersten, T. Intestinal lysosomal enzyme activity in regional simulated shock: Influence of methylprednisolone and albumin. Circ. Shock 4: 27, 1977.

14. Haglund, U., Myrvold, H., and Lundgren, O. Cardiac and pulmonary function in regional intestinal shock. Arch. Surg. 113: 963, 1978.

15. Kazmers, A., Wright, C. D., Whitehouse, W. M., Jr., Zelenock, G. B., Lindenauer, S. M., and Stanley, J. C. Glucagon and canine mesenteric hemodynamics: Effects on superior mesenteric arteriovenous and nutrient capillary blood flow. J. Surg. Res. 30: 372, 1981.

16. Kazmers, A., Zwolak, R., Appelman, H. D., Whitehouse, W. M., Jr., Wu, S-C. H., Zelenock, G. B., Cronenwett, J. L., Lindenauer, S. M., and Stanley, J. C. Pharmacologic interventions in acute mesenteric ischemia: Improved survival with intravenous glu- 
cagon, methylprednisolone, and prostacyclin. Presented at the 7th Annual Meeting of the Midwestern Vascular Surgical Society, Chicago, Illinois, September 23, 1983. Surgery, in press.

17. Lanciault, G., Fang, W.-F., Jacobson, E. D., and Bowen, J. C. Evaluation of potential agents for treatment of nonocclusive mesenteric ischemia in the dog. Circ. Shock 3: 239, 1976.

18. Lundgren, O., Haglund, U., Isaksson, O., and Abe, $T$. Effects on myocardial contractility of blood-borne material released from the feline small intestine in simulated shock. Circ. Res. 38: 307, 1976.

19. Madden, J. J., Jr., Ludewig, R. M., and Wangensteen, S. L. Effects of glucagon on the splanchnic and the systemic circulation. Rev. Surg. 29: 372, 1972.

20. Maxwell, L. C., Shepherd, A. P., and Riedel, G. L. Vasodilation or altered perfusion pressure moves 15 $\mu \mathrm{m}$ spheres trapped in the gut wall. Amer. J. Physiol. 243: H123, 1982.

21. Norlen, K., Rentzhog, L., and Wikstrom, S. Hemodynamic effects of phenoxybenzamine and volume replacement in segmental ischemia of the rat small intestine. Acta Chir. Scand. 144: 299, 1978.

22. Ottinger, L. W., and Austen, W. G. A study of 136 patients with mesenteric infarction. Surg. Gynecol. Obstet. 124: 251, 1967.

23. Pawlik, W. W., Fondacaro, J. D., and Jacobson, E. D. Metabolic hyperemia in canine gut. Amer. $J$. Physiol. 239: G12, 1980.

24. Rudolf, A. M., and Heymann, M. B. The circulation of the fetus in utero. Circ. Res. 21: 163, 1967.

25. Schwaiger, M., Fondacaro, J. D., and Jacobson, E. D. Effects of glucagon, histamine, and perhexiline on the ischemic canine mesenteric circulation. Gastroenterology 77: 730, 1979.

26. Seelig, R. F., Kerr, J. C., Hobson, R. W., II, and Machiedo, G. W. Prostacyclin (Epoprostenol). Its effect on canine splanchnic blood flow during hemorrhagic shock. Arch. Surg. 116: 428, 1981.

27. Tibblin, S., Kock, N., and Schenck, W. G., Jr. Splanchnic hemodynamic responses to glucagon. Arch. Surg. 100: 84, 1970.

28. Tyler, G., Clark, R. A., and Jacobson, E. D. Nonocclusive intestinal ischemia treated with intraarterial infusion of prostaglandin $\mathrm{E}_{1}$. Cardiovasc. Intervent. Radiol. 5: 16, 1982.

29. Williams, L. F., Anastasia, L. F., Hasiotis, C. A., Bosniak, M. A., and Byrne, J. J. Experimental nonocclusive mesenteric ischemia. Arch. Surg. 96: 987, 1968. 